\title{
APORTACIONES AL ESTUDIO DE LA SARGA (ALCOY, ALICANTE)
}

\author{
J. EMILIO AURA TORTOSA \\ Universidad de Salamanca \\ A Carmen
}

\begin{abstract}
En el presente trabajo se estudia la fase cromática más antigua de la Sarga (Alcoy, Alicante), infrapuesta al Arte Levantino y que adquiere vital transcendencia en función de los últimos descubrimientos, pudiendo aislar un nuevo horizonte artístico anterior al Arte Levantino, al menos en las comarcas del Norte de la Provincia de Alicante.
\end{abstract}

This paper deals with a study on the older chromatic phase from La Sarga (Alcoy, Alicante), which is underlaid to the Levantine Art. It is specially important with regard to the last discoveries, because it permits to isolate a new artistic outlook, previous to the Levantine Art, at least in the Northern districts of the province Alicante.

$\mathrm{Al}$ iniciar los trabajos encaminados a la realización de nuestra Memoria de Licenciatura y bajo la amable sugerencia del profesor Jordá, nos propusimos la actualización de la Sarga, publicada en su día por el profesor Beltrán y V. Pascual.

Este transcendental yacimiento, del que esperamos en breve plazo ultimar un estudio monográfico, contiene una clara estratigrafía cromática superponiéndose el más $p u-$ ro Arte Levantino a «numerosos trazos y signos esquemáticos» (BELTRAN, 1974, 47).

Dichas apreciaciones fueron retomadas por el profesor Fortea, paralelizando tales motivos, junto a otros similares de la Cueva de la Araña y Cantos de la Visera (BELTRAN, 1968, 67), con las plaquetas grabadas de Cocina II (FORTEA, 1974, 231), articulando lo que se ha llamado hasta la fecha Arte Lineal-Geométrico.

A raíz del I Coloquio Internacional de Arte Esquemático celebrado en mayo de 1982, se dio a conocer por parte de M. Hernández Pérez y del Centre d'Estudis Contestans, una serie de conjuntos que por tamaño y temática se acercan a la fase más antigua de la Sarga.

Los abrigos inventariados con este nuevo tipo de Arte son los siguientes (M. HERNANDEZ PEREZ y C. E. C., 1982, 7):

- Plà de Petracos

- Racò de Sorellets

- Tollos

- Coves Rojes de Benimassot

- Barranc de L'Infern de Fleix, encontrándose tanto aislado como asociado al Levantino y/o Esquemático, como vemos en un área muy delimitada al norte de la provincia de Alicante.

En todos ellos concurren características que los acercan y distancian al mismo tiempo de la Sarga, sin embargo podemos considerarlos de un mismo horizonte cultural en 


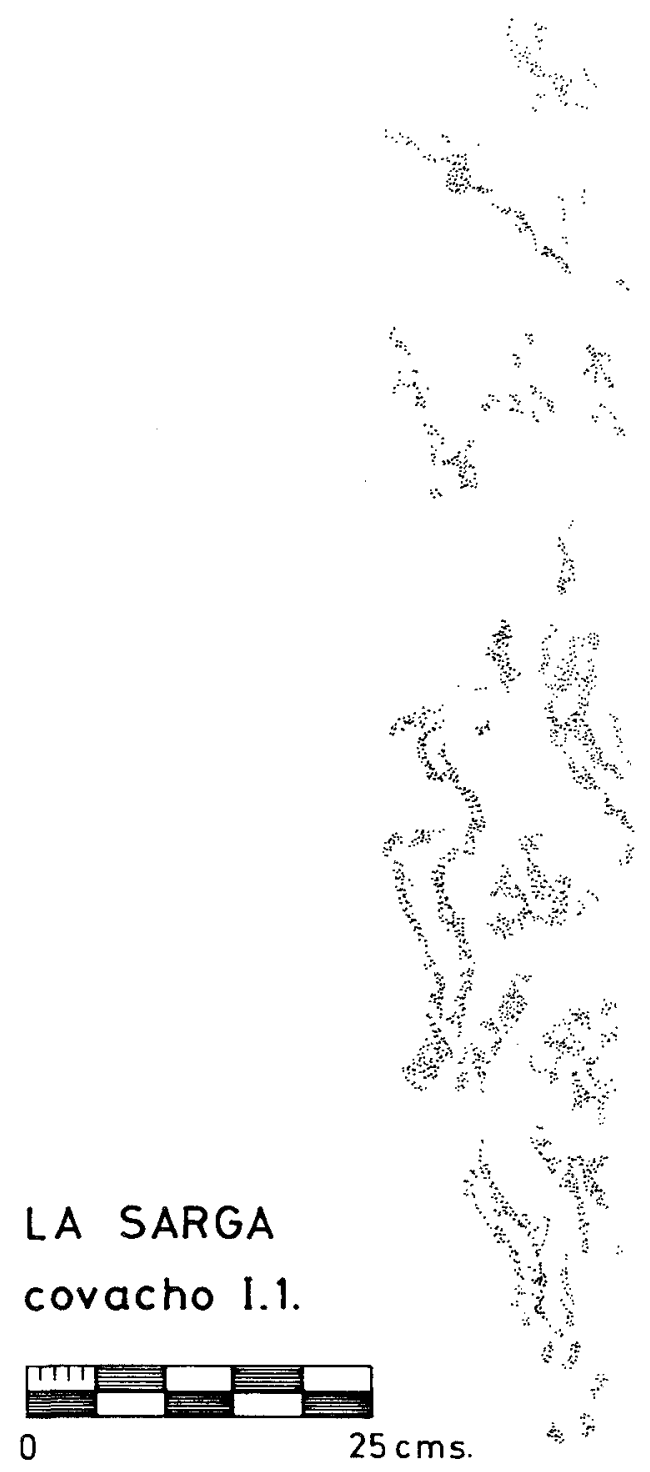

Figura 1. Covacho I.1. (calcos del autor).

base a las comparaciones temáticas y estilísticas (M. HERNANDEZ PEREZ y C. E. C., $1982,8)$.

Bajo el epígrafe Sarga I, incluimos todos los motivos infrapuestos a los ciervos levantinos del Covacho I, sector «a» (BELTRAN, 1974, fig. 4). Asimismo consideramos que tanto por su temática y técnica son también adscribibles a esta etapa los meandriformes y gran figura humana tocada con cuernos del Covacho II (BELTRAN, 1974, figs. 7 y 8), pudiendo asignar también a este horizonte algunos signos, muy deteriorados, que se reparten por los Covachos II y III. 


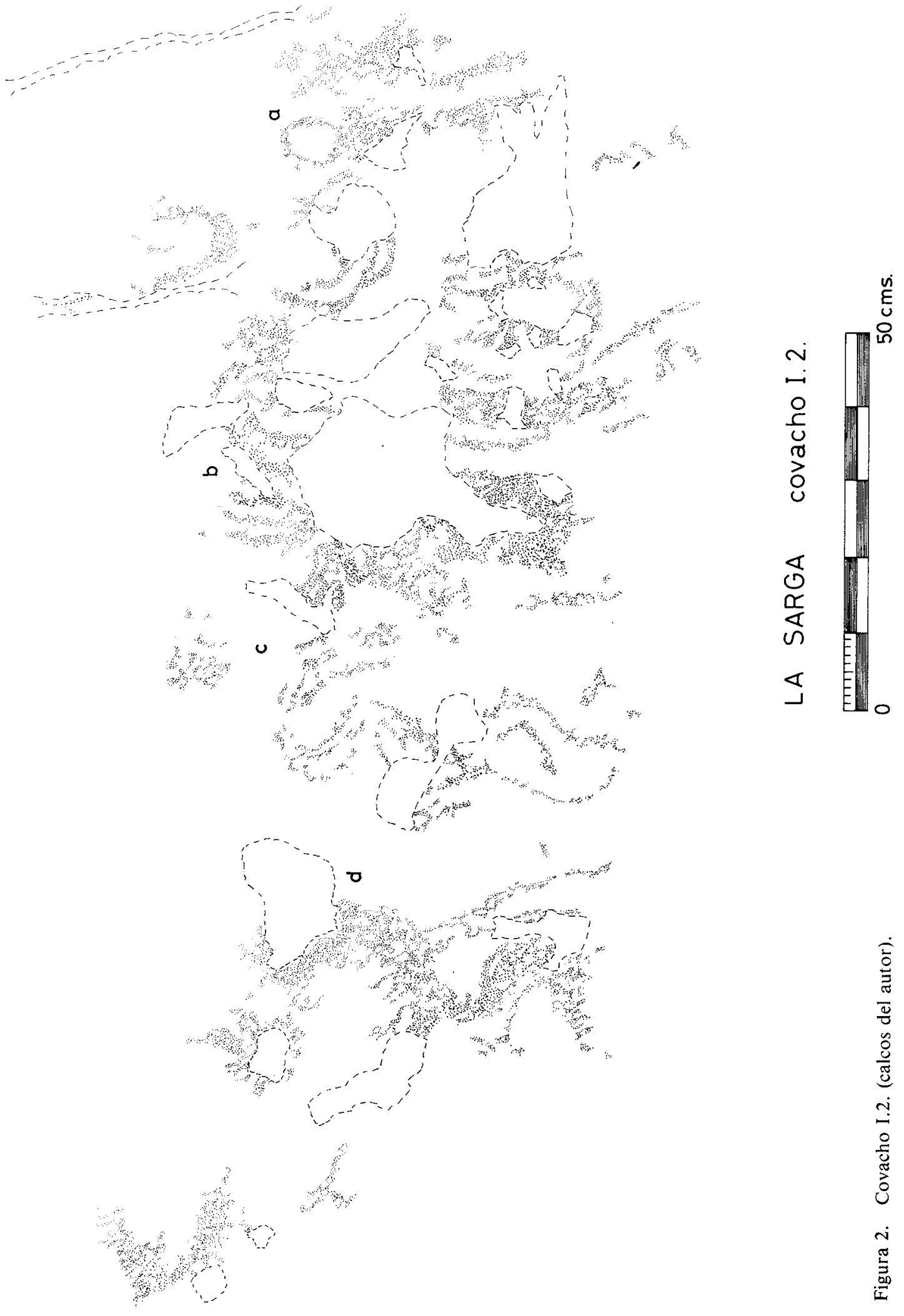


No vamos a realizar una descripción exhaustiva de los motivos de Sarga I, ya que fueron descritos en su día por el profesor Beltrán; sin embargo unas someras referencias nos pueden servir de introducción.

En el primer abrigo, subdividido por nosotros en tres paneles básicos, es posible advertir un buen número de los caracteres generales de este nuevo horizonte artístico.

El primer panel (Covacho I. 1) lo forma un serpentiforme de desarrollo vertical y trazo más o menos anguloso (fig. 1). Por su situación marginal y un tanto desprovisto de la protección de la visera del abrigo, su conservación no es muy buena.

En el segundo panel (Covacho I. 2) hemos señalado cuatro motivos fundamentales (fig. 2). La figura humana señalada con la letra «a», realizada mediante el convencionalismo de representar la cabeza por medio de un círculo y el cuerpo por un simple trazo

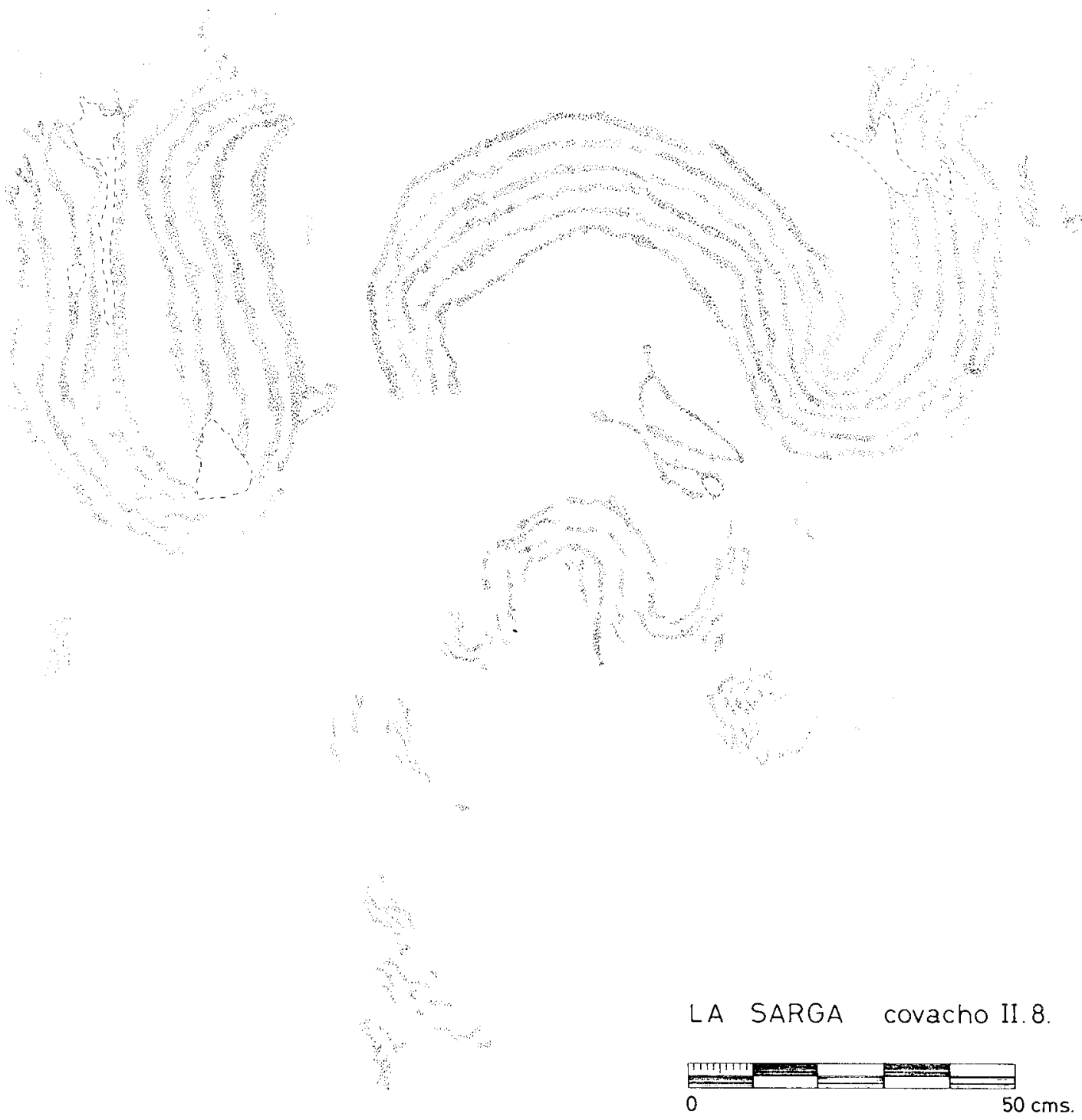

Figura 3. Covacho II.8. (calcos del autor). 


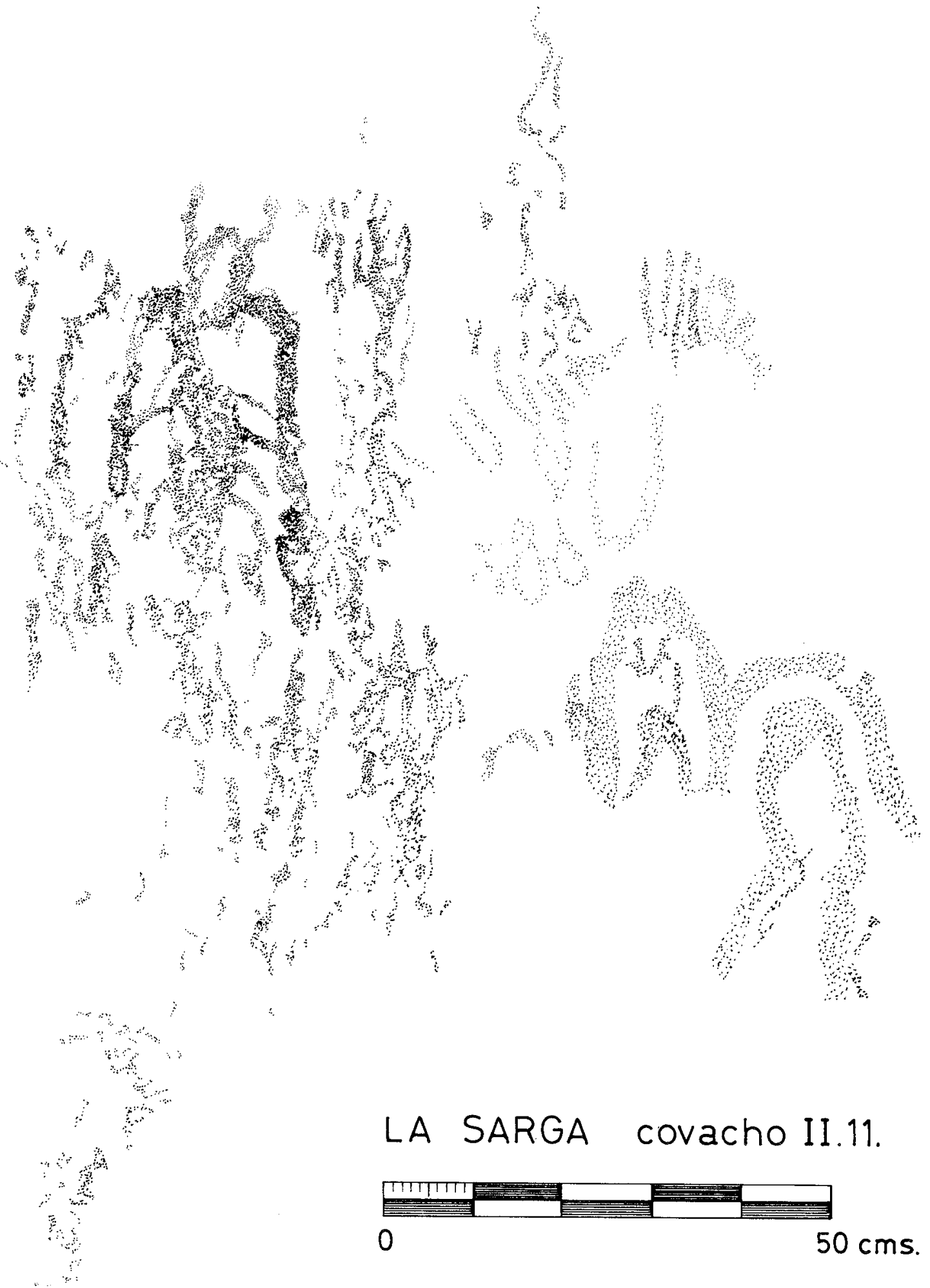

Figura 4. Covacho II.11. (calcos del autor). 
vertical y a la que nos referiremos ampliamente en páginas siguientes. De los otros tres motivos, letras «b», «c» y «d», sólo señalar el ritmo curvilíneo y las barras paralelas del motivo I. 2. b, presentes también en el Covacho II. 11.

En el Covacho II hemos aislado 11 paneles; dos de ellos al menos presentan claros motivos adscribibles al horizonte Sarga I por sus características temáticas y estilísticas. Hay que destacar en primer lugar los grandes meandriformes (Covacho II. 8), terminados bien en apéndices radiados, bien en pequeños círculos (fig. 3); pero es sin duda la gran figura humana del Covacho II. 11. el motivo más extraordinario de toda esta primera fase; en él se observan ciertos convencionalismos anteriormente apuntados (figura 4).

\section{ASPECTOS TECNICOS Y TEMATICOS}

La primera característica esencial y diferenciadora es el gran tamaño de los motivos, realizados mediante trazo de ancho irregular, lo que nos recuerda la fase AuriñacoGravetense del Arte Paleolítico aunque es imposible toda correlación cronológicocultural.

El color empleado en la mayoría de los casos es el rojo oscuro y rojo violáceo, destacando el gran personaje del Covacho II. 11. realizado en negro; posiblemente tal coloración sea resultado de la fuerte oxidación y calcificación de la pintura roja que se advierte todavía en algunos puntos del mismo, aunque este hecho también puede deberse a repintados posteriores.

En cuanto a la temática, recientemente hemos podido consultar un original (M. HERNANDEZ PEREZ y C. E. C., 1983), en el que se señalan dos grupos claramente diferenciados:

- Figuras humanas.

- Motivos geométricos.

Esta clasificación inicial nos parece perfectamente aceptable y, siguiendo a los citados autores, admitimos para la Sarga el convencionalismo en la representación de la cabeza en la figura humana mediante un círculo, hecho que se repite tanto en el Covacho I. 2. (fig. 2), como en el II. 11. (fig. 4).

En cuanto al segundo grupo, el de los geométricos, nos merece especial interés por cuanto la variedad y riqueza de formas, no exclusivas de Sarga I, concurren en un aspecto esencial que ya fue señalado en su día: la obsesión por la curva en todas sus variantes (M. HERNANDEZ PEREZ y C. E. C., 1982, 8). Así recogemos motivos serpentiformes, meandriformes, etc., en definitiva curvilíneos, terminados también en algún caso en apéndices radiados (fig. 3).

Junto a estos motivos de trazo grueso y desigual, encontramos otros de ancho más fino y de menor tamaño que en la mayoría de los casos presentan un perfil más anguloso y rectilíneo en oposición a los anteriores. Estos motivos no se encuentran infrapuestos al Arte Levantino en la Sarga, pero sí parecen ser los tipos hallados en la Cueva de la Araña y Cantos de la Visera por debajo del Arte levantino.

Esta matización en base a la subdivisión de los motivos geométricos según grosor de trazo, tipo de perfil (anguloso y curvilíneo) y tamaño, nos parece fundamental para aislar y diferenciar los elementos iconográficos que componen Sarga I.

\section{ANALISIS Y RELACIONES}

Sin duda la denominación Arte Lineal-Geométrico responde parcialmente a la realidad conceptual de Sarga I si atendemos a la presencia de figuras humanas. Si en términos técnicos es explicativa, temáticamente crea confusión al no recoger la presencia de figuras humanas. 
Recientemente M. Hernández Pérez y el Centre d'Estudis Contestans han propuesto provisionalmente la denominación de Arte Macroesquemático, señalando que no tiene relación alguna con el «tradicional Arte Esquemático».

Sea cual fuere su denominación final, estamos ante un horizonte artístico anterior al Arte Levantino según se desprende de la clara estratigrafía cromática de la Sarga (BELTRAN, 1974, 46) y posiblemente también de la del Abric IV del Barranc de Benialí (M. HERNANDEZ PEREZ y C. E. C., 1982, 10), lo que nos sitúa de lleno en el problema del origen del Arte levantino.

No vamos a exponer aquí las controvertidas teorías de tres grandes investigadores del Arte Levantino, profesores Ripoll, Beltrán y Jordá. Sus argumentos en favor y en contra de unos límites cronológico-culturales determinados están ampliamente repetidos.

Intentaremos construir, partiendo de los dos grupos fundamentales de motivos, una hipótesis de trabajo que confiamos no resulte dogmática y anquilosada.

En primer lugar cabe destacar la ausencia, transcendental y significativa, de paralelos para esta fase de la Sarga, y por extensión de todo este nuevo horizonte artístico, con el Arte Mueble.

Ello sin embargo no debe ser freno para la formulación de un marco cronológicocultural partiendo tanto de la iconografía como de la datación atribuible a Sarga II, superpuesta a los motivos que nos ocupan, aunque ello entrañe dificultades por el desconocimiento del tiempo transcurrido entre la realización de una y otra fase.

Como ya se ha señalado anteriormente es posible la subdivisión en dos grandes grupos de los motivos de Sarga I. Partiendo de este hecho encontramos que todo posible paralelo para las representaciones curvilíneas habría que buscarlo o bien en las plaquetas del Magdaleniense III-IV de Parpalló (PERICOT, 1942, 114 ss.), grabadas en su mayoría y de reducido tamaño, o bien en los serpentiformes pintados en rojo de la Pileta (BREUIL, OBERMAIER y VERNER, 1915). Tales paralelos nos parecen inviables no sólo técnica y estilísticamente, sino también por su ubicación y entorno arqueológico, ausencia de auténticas figuras humanas, etc.

En cuanto al segundo grupo de motivos geométricos, de menor tamaño, perfil anguloso y trazo más fino, presentes en Sarga I, Covacho I. 1. y I. 2. c., . no se encuentran infrapuestos a ningún motivo levantino. Dichos tipos, creemos, son los que se infraponen en Cantos de la Visera (CABRE, 1915, 208, ss.) y Cueva de la Araña (BELTRAN, 1968, 67); apareciendo en otros yacimientos, ya sin estratigrafía cromática, como son Solana de las Covachas en Nerpio (ALONSO TEJADA, 1980, 56), los nuevos grupos de Bicorp (MONZONIS y VIÑAS, 1981, fig. 12), etc.

Para ambos grupos es posible ver antecedentes; a los ya mencionados habría que unir quizás un buen número de los ideomorfos de la Cueva de la Pileta (JORDA, 1978, 92); podemos por tanto intuir un sustrato que sirve de antecedente a todo este tipo de representaciones, y que por su dispersión parece eminentemente mediterráneo.

En definitiva una gran corriente geométrica y lineal que se inicia en el Solutrense de Parpalló, está presente en el Magdaleniense, continúa durante los momentos finales del Epipaleolítico, al menos de facies geométricas, con Cocina II, y llega hasta el Neolítico cardial con los huesos grabados de la Cova de la Sarsa (FORTEA. 1974, 236).

El tercer grupo de representaciones, las figuras humanas, presenta una problemática especial. No hemos encontrado ni en el Arte Paleolítico ni en el Epipaleolítico paralelos ni antecedentes posibles. Están muy lejos de estos motivos de la Sarga, por técnica, tamaño y valor conceptual, los antropomorfos paleolíticos, ya que nos encontramos ante auténticas representaciones humanas, esquemáticas si se quiere, y no meras idealizaciones. 
Ello nos sitúa ante un aspecto polémico: el de los orígenes y cronología del Arte Levantino. Sucintamente vamos a exponer las características que concurren en Sarga II a modo de referencia; vuelvo a incidir en un hecho apuntado con anterioridad; desconocemos el lapso de tiempo transcurrido entre la plasmación de uno y otro tipo de representaciones.

Sin duda los cérvidos de Sarga II, independientemente de la aparición de arqueros, podrían ser incluidos en las fases naturalistas de Ripoll y Beltrán, hecho apuntado en su día al determinar «que los animales siguen la tradición de la fase I», con una cronología aproximada a partir del año 4000 (BELTRAN, 1974, 48).

Por otra parte las cinco puntas de flecha pedunculadas del Covacho III, fechables en momentos Eneolíticos como apunta el profesor Jordá, y lo que nosotros sí interpretamos como una clara escena de vareo, aunque para ésta es posible admitir una cronología más amplia (Covacho I, sector «b» de BELTRAN), todo ello podría situarnos dentro de una economía agrícola.

En este orden de cosas, uno de los aspectos que se ha venido manejando para la adscripción al Epipaleolítico del Arte Levantino, ha sido la presencia abrumadora de escenas de caza, frente a un número menor de escenas agrícolas (JORDA, 1974), o de cualquier otro tipo.

Si recurrimos al estudio paleontológico de la cercana Cova de l'Or, con domesticación de plantas y animales plenamente constituida (MARTI OLIVER, 1980), podemos entrever algunos aspectos interesantes. Así el total de especies domesticadas supone el 73,7 por ciento, aunque «los animales salvajes económicamente importantes ocupan un 16,4 por ciento del total de restos» (PEREZ RIPOLL, 1980, 243). Encontramos pues en un yacimiento clásico neolítico un aporte importante, a mi modo de ver, basado en la caza de cérvidos fundamentalmente.

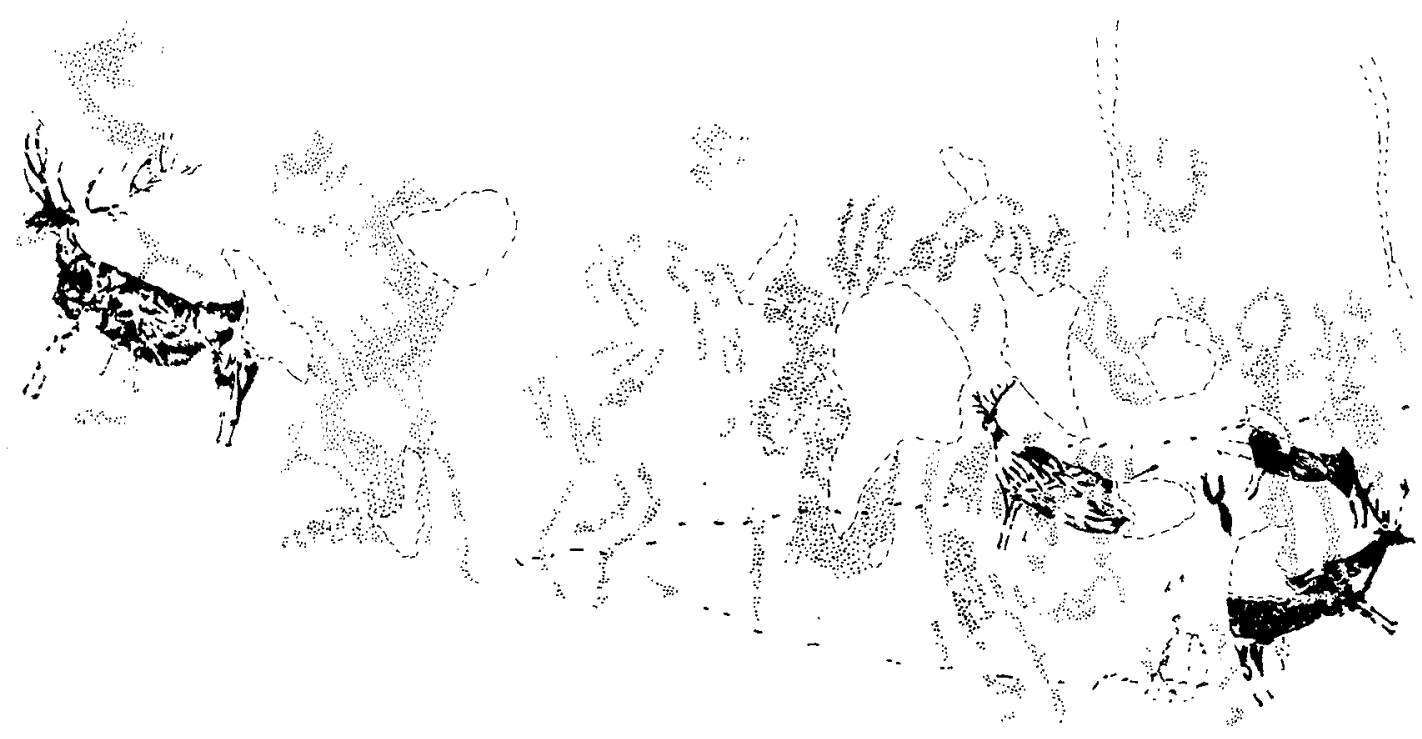

\section{LA SARGA 1.2}

superposicion

$25 \mathrm{cms}$.

Figura 5. (Calcos del autor) 

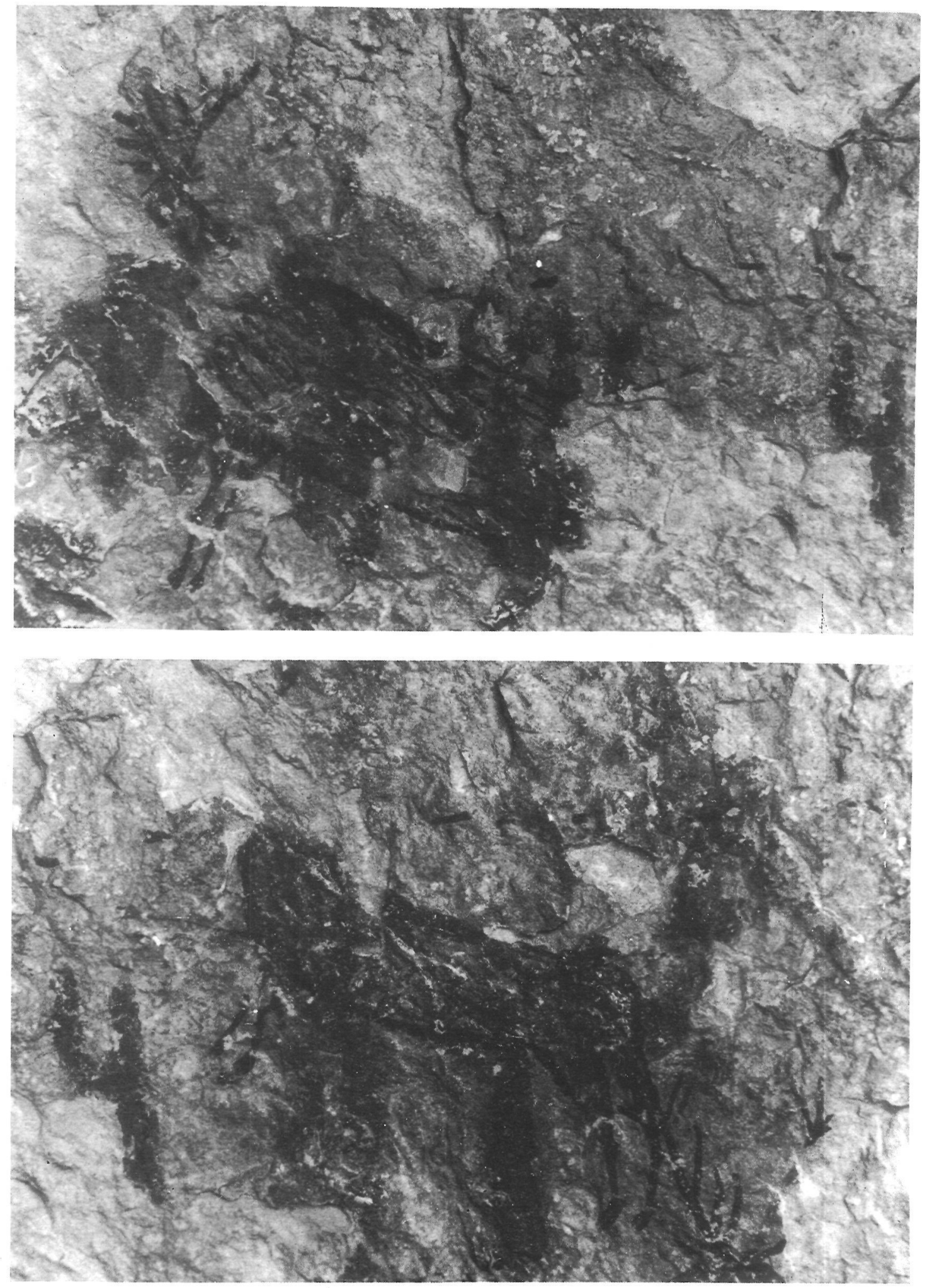

Lámina I. 
En definitiva tanto la escena de recolección, como las puntas de flecha, junto a algún posible paralelo con el Arte Mueble, no suficientemente confirmado (1), apuntan hacia un horizonte cronológico-cultural Neolítico y Eneolítico en sentido amplio.

Quizás un estudio comparativo de las especies representadas y restos paleontológicos de los yacimientos cercanos nos aportará algún dato explicativo, cronológicamente hablando, aunque para ello habría que tener en cuenta los condicionamientos orográficos que pueden influir en la presencia o ausencia de determinadas especies, capacidad de adaptación, etc.

\section{PROBLEMATICA Y CONCLUSIONES}

Como ya se ha enunciado en alguna ocasión (BELTRAN, 1974, 46 ss.; M. HERNANDEZ PEREZ y C. E. C., 1983), el problema fundamental es si este nuevo horizonte artístico, ya sea denominado lineal-geométrico, lineal-figurativo o macroesquemáti$c o$, puede ser la base generativa del Arte Levantino, al menos para este área meridional.

Hemos insistido también en la trascendental importancia que adquiere la presencia de figuras humanas, careciendo hasta la fecha de todo posible paralelo fuera de este reducido núcleo valenciano.

El problema parece de difícil solución pues no es fácil comparar estas impresionantes representaciones humanas, que en algún caso alcanzan el metro de altura, con las gráciles y naturalistas figuras levantinas.

Sin embargo podemos enunciar algunos aspectos que nos permitirán avanzar en futuros trabajos, asentándose como base de nuevas hipótesis de trabajo.

I. Parece evidente un sustrato artístico geometrizante desde etapas paleolíticas para todo el Mediterráneo, y que perdura hasta tiempos Preneolíticos - Cocina II- e incluso Neolíticos con el hueso grabado de la Cova de la Sarsa, donde se intuye un buen número de ídolos Neolíticos-Eneolíticos.

II. La presencia de figuras humanas en Sarga I, sólo nos parece explicable dentro de un contexto de relación y/o reproducción de formaciones económicas neolitizadas o neolíticas.

III. Los elementos innovadores, sin querer entrar en polémicas sobre difusionismo, aculturación, etc., se nos muestran imbricados con una tradición autóctona, aunque no nos sea posible la delimitación real del valor conceptual asignado a este tipo de motivos.

IV. El marco cronológico-cultural para las pinturas levantinas de la Sarga, creemos que debe adelantarse hasta un Neolítico final-Eneolítico en espera de posibles paralelos mobiliares (ver nota 1 ).

Por todo ello las bases materiales para este horizonte artístico creo que debemos buscarlas en el singular proceso de Neolitización del País Valenciano, definible escuetamente como «más que tres facies neolíticas, veríamos un Neolítico, una neolitización y un contacto sin porvenir», (FORTEA, 1973, 471).

Es en ese lapso de tiempo transcurrido entre las plaquetas de Cocina II (Epipaleolítico final) y la realización de las figuras levantinas de la Sarga (Neolítico finalEneolítico), cuando asistimos bien a la simbiosis de dos concepciones artístico-

(1) Agradecemos a B. MARTI OLIVER la utilización de este nuevo dato, más si cabe al ser inédito. El motivo en cuestión está realizado sobre un fragmento cerámico de Cova de l'Or (Campaña 1982). Sin embargo, las dificultades inherentes a toda excavación imponen la necesidad de una comprobación, necesaria para evitar interpretaciones aventuradas. 

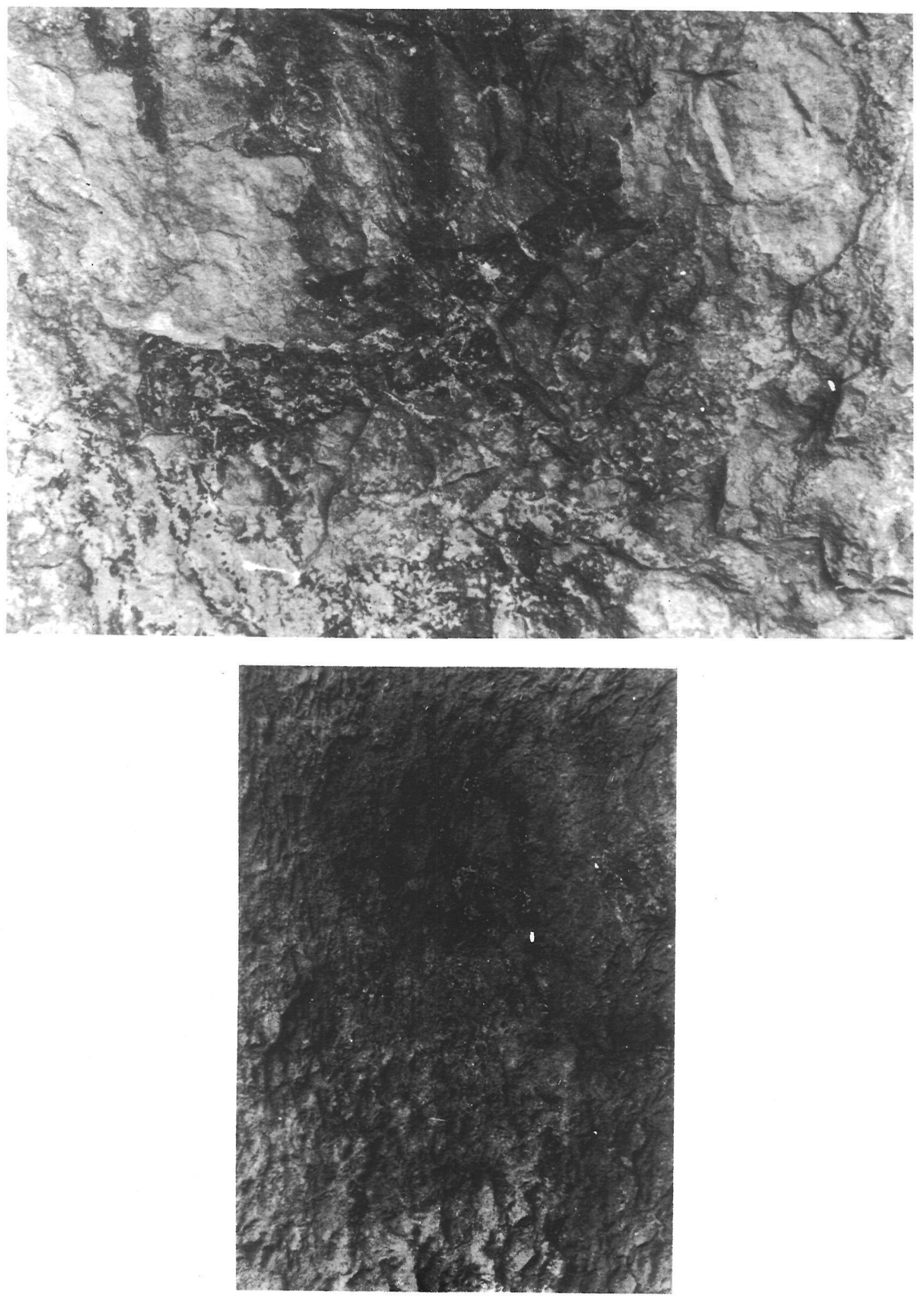

Lámina II. 
religiosas: sustrato indígena geometrizante más elementos figurativos exógenos, bien a la creación de un nuevo elemento iconográfico de singular trascendencia: la figura humana.

Esperamos que en breve las críticas y aportaciones ratifiquen y/o enmienden estas primeras hipótesis de trabajo. Sin duda el Arte Levantino ha sido, es y seguirá siendo uno de los aspectos más controvertidos de la Prehistoria Peninsular.

\section{BIBLIOGRAFIA}

ALONSO TEJADA, A.: 1980. El conjunto rupestre de Solana de las Covachas. Nerpio (Albacete). Albacete. BELTRAN MARTINEZ, A.: 1968. Arte Levantino. Zaragoza.

BELTRAN MARTINEZ, A. y col. de PASCUAL PEREZ, V.: 1974. Las pinturas rupestres prehistóricas de la Sarga (Alcoy), El Salt (Penáguila) y El Calvari (Bocairente). Valencia.

BREUIL, H., OBERMAIER, H., VERNER, P.: 1915. La Pileta à Benaoján (Málaga, Espagne). Mónaco. CABRE AGUILO, J.: 1915. El Arte Rupestre en España. Madrid.

FORTEA PEREZ, F. J.: Los complejos microlaminares y geométricos del Epipaleolítico mediterráneo español. Salamanca.

- 1974. «Algunas aportaciones a los problemas del Arte Levantino». Zephyrus XXV. Salamanca. Pp. 225-257.

HERNANDEZ PEREZ, M. y CENTRE D'ESTUDIS CONTESTANS: 1982. «Arte Esquemático del País Valenciano. Recientes aportaciones». Coloquio Intern. de Arte Esquemático de la Península Ibérica. Salamanca.

- 1983. «Consideraciones sobre un nuevo tipo de Arte Prehistórico». (Agradecemos la consulta de este original en prensa).

JORDA CERDA, F.: 1974. «Las representaciones de danzas en el Arte Rupestre Levantino». III Congr. Nac. Arq., Porto.

- 1975. «Las puntas de flecha en el Arte Levantino». XIII Congr. Nac. Arq. Pp. 219-226.

JORDA CERDA, F. y BLAZQUEZ, J. M.: 1978. Historia del Arte Hispánico. I. La Antigüedad 1. Madrid. MARTI OLIVER, B. et alii.: 1980. Cova de l'Or (vol. II). Valencia.

MONZONIS, F. y VIÑAS, R.: 1981. «Cinco nuevos abrigos con Arte Rupestre en la zona de Bicorp (Valencia)». Simpósium Altamira. Madrid. Pp. 379-410.

PEREZ RIPOLL, M.: 1980. «La fauna de vertebrados» en Cova de l'Or (vol. II). Valencia. Pp. 193-256.

PERICOT, L.: 1942. La Cueva de Parpalló (Gandía). Madrid.

RIPOLL PERELLO, E.: 1968. «Cuestiones en torno a la cronología del Arte Rupestre Postpaleolítico en la Península Ibérica». Simpósium de Arte Rupestre. Barcelona. 